\title{
LAS NOVELAS HISTÓRICAS OLVIDADAS DE BLASCO IBÁÑEZ
}

\author{
Ana L. Baquero Escudero \\ Universidad de Murcia
}

\section{El RELATO HISTÓRICO EN LA PRODUCCIÓN NARRATIVA DE BLASCO}

Dentro de la dilatada producción narrativa de Vicente Blasco Ibáñez, destaca con especial relieve el relato de tipo histórico. Desde luego sus tanteos y comienzos literarios pueden, sin duda alguna, ser adscritos a este género tanto en lo que concierne a sus novelas como a sus relatos breves. Su primer libro constituido por un conjunto de cuentos bajo el título de Fantasías aparecido en 1887, reúne así un conjunto de relatos de clara tonalidad romántica caracterizados como el cuento de dicha tendencia, por la ambientación medieval, el exotismo y en general, todo un nutrido grupo de motivos y tópicos propios de aquella estética, sin duda en estas fechas, ya totalmente superada. Relatos de corte histórico, sus títulos resultan de por sí emblemáticos respecto a su naturaleza y características - «La misa de medianoche», «Tristán el sepulturero», «El castillo de la Peña Roja», «La espada del templario»...-. Un tipo de narración breve que Blasco abandonaría en su posterior cultivo del género cuentístico y que como otro grupo de su producción novelesca, el escritor llegaría a rechazar.

Del lado por otra parte, de dicha obra novelesca, resulta asimismo significativo constatar cómo sus primeras producciones caen de lleno también en el ámbito del relato histórico. De esa etapa inicial que el escritor calificaría de basura romántica, y de la que renegaría, buena parte la constituyen novelas históricas. Un género al que Blasco sería singularmente fiel y que quizá también significativamente, cierra su dilatada obra novelística. 
Escritor de gran éxito y ventas, si gozó pronto del favor del público no consiguió por el contrario como se suele repetir, el reconocimiento de una élite literaria, si bien especialmente su producción novelesca y en concreto el ciclo de las denominadas novelas valencianas, suscitó pronto elogiosos comentarios y análisis críticos. Resulta al respecto sintomático que ya en vida del escritor surgieran diversos intentos por catalogar y clasificar sus novelas. Sin duda uno de los más significativos, el del propio Blasco. En tales clasificaciones que se han prolongado con sus diversas variantes hasta nuestro días, resulta curioso constatar cómo el criterio de catalogación -posiblemente a raíz de la propia visión del escritor ${ }^{1}-$, gira fundamentalmente en torno a unos factores específicos de naturaleza sin duda más extrínseca que intrínsecamente literaria. Es así la circunstancia vital del propio Blasco tan cambiante y tan singularmente novelesca, lo que se suele manejar para marcar las distintas tendencias en su evolución narrativa. Así al hilo de sus propios cambios de vida, Blasco en ese famoso y valioso documento personal que es la famosa carta a Cejador, establecerá diversos períodos en su obra novelesca, desde ese inicial ciclo valenciano -tan ligado aún el autor a sus orígenes patrios-, pasando por esa novela social o de tendencia íntimamente vinculada a sus principios ideológicos, hasta esas novelas cosmopolitas, cuando se desvincula del ambiente natal, o esas proyectadas novelas americanas que surgen a raíz de sus contactos con aquel continente, o las que escribe como consecuencia de su toma de postura ante el estallido de la Guerra Mundial.

Con peculiares y personales variantes, Andrenio en El Renacimiento de la novela en el siglo XIX, aparecida en 1924, establece cuatro apartados en las obras de Blasco: las novelas valencianas -y en esta primera etapa y las obras que la constituyen hay una significativa unanimidad entre los críticos e historiadores-, las novelas de las profesiones artísticas, las novelas de las ciudades y de los medios sociales, y las novelas cosmopolitanas, de viaje, de la emigración y de la guerra (Gómez de Baquero, 1924: cap. X). Quizá lo que aparta la clasificación de Andrenio de la de otros autores, es la consideración aparte de Sónnica la cortesana, obra que cataloga como novela histórica, «episodio de la antigua Sagunto»². No deja de resultar por tanto,

1. La temprana de González Blanco, por ejemplo, sigue de cerca los criterios establecidos por el novelista (González Blanco, 1920).

2. Blasco expresó su opinión adversa a la consideración aislada de esta obra que él incluía dentro del ciclo de las novelas valencianas. Recordando las novelas anteriores a la misma, de temática regional, escribiría: «La tierra valenciana ya no podía dar más de sí: la había explotado en todos los sentidos. Y entonces fue cuando remontándome en el pasado, quise pintar el hecho más heroico de la historia valenciana, la defensa de Sagunto, e hice Sónnica la cortesana» Citado por Camille Pitollet, 1957: 345. 
representativo que bajo la perspectiva de este crítico, Sónnica ocupara un lugar aparte y que sólo en esta ocasión el crítico utilizara como criterio catalogador un género determinado de novela, que tan floreciente aparece por otro lado, en la centuria decimonónica.

De alguna forma Eduardo Zamacois se hace eco también del manejo de este subgénero novelesco al revisar la producción de Blasco. Posterior su trabajo al mencionado de Andrenio, y fallecido Blasco, Zamacois tiene en cuenta la totalidad de la producción novelística publicada por el escritor valenciano. Y así si alude a las novelas regionales y a las novelas de rebeldía, incluye dentro de la tercera época, La maja desnuda, Sangre y arena y Los muertos mandan, para mencionar finalmente las novelas cosmopolitas. Pues bien refiriéndose a estas últimas concretará: «que yo denominaría del Espacio para mejor distinguirlas de las históricas o novelas del Tiempo, que aparecerán después» (Zamacois, 1928: 111). Unas novelas históricas con las que efectivamente Blasco Ibáñez concluirá su producción literaria, sin poder llevar adelante por su temprana muerte, los diversos proyectos que dejó apuntados, entre los que contaban otras novelas históricas sobre diversos conquistadores españoles.

Como puede constatarse tan sólo por esta concentrada revisión de los intentos clasificatorios de la novelística de Blasco, por lo general y salvo la mención incluso por parte del autor, de las novelas de tesis -ese género con el que irrumpirá propiamente el realismo novelesco en España en la década de los $70^{3}-$, se suele manejar el criterio temático y no el propiamente genérico para diferenciar sus distintas etapas. Así novelas valencianas -y no realistas o naturalistas de carácter regional-, de la guerra o americanas. Si bien es cierto en ocasiones la crítica maneja tipos narrativos concretos para calificar sus obras como novela psicológica o de aventuras $^{4}$.

Contemplada, pues, desde una perspectiva global la producción de Blasco, la novela histórica, ese género que experimentará un destacado relieve desde los inicios del S. XIX, adquiere un destacado lugar ${ }^{5}$. Como indica León Roca, la primera narración que el autor vio publicada fue un breve relato que Llombart traduciría al valenciano, de tipo histórico que

3. Y que por supuesto en manos de Blasco presenta características peculiares hasta el punto de considerarse representativa de una modalidad novelesca distinta. Oleza hablará así, de las novelas del realismo social. Oleza, 2000.

4. Sobre los diversos intentos clasificatorios de la novelística de Blasco, puede consultarse la muy útil visión panorámica que ofrece Enrique Rubio (2002: 648-650).

5. Por lo demás hay que dejar constancia desde un primer momento del enorme interés del escritor por la Historia, reflejado tan explícitamente en obras como su Historia de la Revolución española o su posterior Historia de la guerra europea. 
tituló La Torre de la Boatella, incluido en el Almanaque Lo Rat Penat ${ }^{6}$ de 1883. Una breve narración en la que el escritor exalta en esta ocasión el patriotismo de los antiguos árabes valencianos en su lucha contra el enemigo cristiano $^{7}$. Dejando a un lado tal relato y algún otro de semejante índole, así como esa mencionada colección de cuentos, en 1888 el autor publicará tres obras de tipo histórico. Una de ellas es realmente un breve ensayo con el que consiguió el premio de los Juegos Florales, dedicado a la memoria de un guerrero valenciano ilustre -Hugo de Moncada-, mientras que las otras dos responden respectivamente a la catalogación de novela histórica, aquí netamente romántica, y de episodio nacional: El conde Garci-Fernández. Novela histórica del Siglo $X^{8}$ y ¡Por la Patria! (Roméu el guerrillero) ${ }^{9}$. Unos años después en 1893 y 94 aparecerá ;Viva la República! que va acompañada del epígrafe Novela histórica y que se suele incluir en la novela folletinesca, junto con otras dos: La araña negra (1892-93) y Los fanáticos (1895). Estas últimas consideradas en alguna ocasión como obras próximas al episodio nacional (Alborg, 2001: 1024 y ss).

Perteneciente como se indicó, a una etapa distinta, en 1901 aparecerá Sónnica la cortesana, volviendo Blasco a manejar el género histórico en esas novelas de exaltación patriótica, concebidas en los últimos años de su vida. De 1925 es El Papa del mar, de 1926 A los pies de Venus, y de 1929 En busca del Gran Kan y El caballero de la Virgen.

A la luz del explícito repudio del propio Blasco de esa inicial etapa marcada por las innegables influencias románticas y especialmente folletinescas, no debe extrañar que los estudios surgidos en torno a las novelas históricas de este escritor se hayan concentrado en estos últimos títulos ${ }^{10}$.

6. Sociedad fundada por Llombart de la que en un primer momento formó parte el escritor (Roca, 2002: 50-51).

7. Esa idealizada visión de aquellos antiguos dominadores de su tierra natal no dejará de estar presente en sus obras de madurez.

8. En las Obras completas El conde Garci-Fernández aparece con la fecha de 1888. Smith en su bibliografía (1976) señala sin embargo, como fecha de la primera edición 1887. Por su parte Antoni Espinós en su utilísimo catálogo de ediciones de la obra de Blasco da para El conde Garci-Fenández también la fecha de 1887. Como muchas de las obras del escritor, apareció en forma de folletín. En general y el mencionado catálogo da buena prueba de ello, la datación cronológica de las distintas ediciones de las obras del escritor valenciano presenta no pocos problemas para el estudioso actual. Espinós, 1998.

9. En 1889 publicaría una novela breve titulada Caerse del nido que junto a la desaparecida Carmen y otras novelas cortas, integrarían esta época primeriza del escritor.

10. Dentro de la bibliografía de Blasco no son con todo, especialmente abundantes los análisis sobre este concreto corpus novelesco. El rastreo por la imprescindible bibliografía de Paul C. Smith arroja a tal respecto, claros resultados sobre el menor interés suscitado por este género en la obra del autor valenciano. Puede verse la última ampliación aparecida en 2005. Como artículos específicos sobre las novelas históricas de Blasco, véanse Martínez Latre (1996), Mata (2000), Anguix (2005), y Almela (2006:130-131). 
Evidentemente muy superiores en calidad literaria a esos primeros intentos en dicho género, con todo y a tenor del sostenido interés del escritor por esta forma novelesca, parece que puede resultar útil considerar esos inicios novelescos para trazar lo que sería la completa evolución del autor en su cultivo de esta especie literaria específica. Siendo imposible desarrollar en las contenciones y limitación del presente estudio tal análisis -que debe quedar pendiente de un futuro estudio a mi modo de ver, necesario e interesante-, y considerando por supuesto, el contexto en el que se presentan estas páginas, en las mismas intentaré aproximarme a ese corpus marginal del escritor valenciano, constituido por esas novelas históricas primerizas. Unas obras que pueden ser consideradas dentro de ese inicial aprendizaje el autor y que pese, evidentemente, a distar en su configuración y calidad de las grandes novelas que el escritor habría de concebir, pueden ofrecer indicios y aun rasgos si se quiere todavía muy atenuados, de algunos de los caracteres literarios propios del gran autor valenciano.

Sirva ello como disculpa y aun justificación para quebrantar los expresos deseos de Blasco Ibáñez en su condena y rechazo absolutos de tales comienzos literarios.

\section{LAS NOVELAS HISTÓRICAS DE BLASCO IBÁÑEZ EN SU CONTEXTO LITERARIO}

Dentro de esa etapa claramente romántica de los inicios novelescos del escritor, pueden incluirse como se mencionó, cinco títulos. De ellos tres se han venido considerando dentro del prototipo narrativo conocido como novela folletinesca y dos dentro del relato histórico. Si bien es cierto $L a$ araña negra y Los fanáticos podrían ser catalogadas dentro de esa novela contemporánea folletinesca próxima como se señaló, en muchos aspectos al episodio nacional, dejaré en esta ocasión su estudio aparte por considerar que en rigor no podrían incluirse dentro de la catalogación de novelas históricas. Realmente en el inicio de Blasco como novelista podría verse la influencia clara del lado de los autores españoles, de ese escritor con quien tuvo un singular contacto, en esa fugaz escapada del joven rebelde a Madrid, tan comentada por sus biógrafos. Me refiero, claro está, a aquel prolífico Fernández y González, cultivador tanto de la novela histórica, como de la folletinesca, ambientada ya en la realidad contemporánea. Dos especies por lo demás, cuyas interrelaciones resultan bastante evidentes (Rubio, 1982). Prescindiendo pues, de estos voluminosos textos nos quedaríamos con esa novela histórica netamente romántica, ambientada en la Edad Media que es El conde Garci-Fernández, con el episodio nacional centrado en la guerra de la Independencia, para exaltar la figura del valen- 
ciano José Roméu, valiente guerrillero en dichas circunstancias históricas, y con ; Viva la República! que recordemos, el propio Blasco calificó de novela histórica. Respecto a ésta estamos ante un caso singularmente curioso que nuevamente encuentra su justificación no tanto en las circunstancias literarias del momento, cuanto en la propia experiencia vital del novelista. Entusiasta de Francia y sus valores republicanos, la obra supone una exaltación de los mismos y de la revolución que constituyó su origen histórico. Ambientada pues, en tal época, se trataría de una de esas obras que recrea no un pasado lejano como fue lo más habitual en la época romántica, sino un período más próximo. Con todo recordemos alguna obra como El golpe en vago de García de Villalta cuya historia transcurre en el S. XVIII. Lo realmente excepcional de la obra de Blasco no resultaría por tanto de su elección del pasado histórico, sino del espacio, ya que frente a la tendencia nacionalista y aun regionalista que imperará en la narrativa histórica a partir de la mitad de siglo, en este caso habría que hablar o bien de un curioso episodio nacional francés o considerando el protagonismo de un héroe español, de un singular episodio internacional. Como quiera que sea y sin prescindir por supuesto, de la naturaleza folletinesca de tal obra que ha hecho que aparezca normalmente relacionada con sus otros folletines, creo que puede tener cabida en el presente estudio, como una variante más de las que empleara Blasco en su utilización de este género.

Para poder valorar en primera instancia la aparición de estas novelas en el ambiente literario de finales de los 80 , debemos en condensada panorámica, trazar un rápido recorrido por la presencia de la novela histórica en estos momentos de nuestra historia ${ }^{11}$. Surgida en los inicios del siglo a raíz del éxito del escocés Walter Scott, será éste el modelo que en primera instancia se imponga entre nuestros novelistas (Zellers, 1931 y 1938), para experimentar no obstante, a lo largo del siglo diferentes transformaciones. No resulta por ello, extraño encontrar en los acercamientos a esta especie por parte de críticos e historiadores, diversos intentos de periodización de la misma dentro de esta coordenada cronológica.

Entre los más tempranos cabría recordar el de Felicidad Buendía (1963), en su distinción de tres etapas bien diferenciadas, siendo quizá los diversos acercamientos de Ferreras a dicho género, aquellos que destacan especialmente por su intento de distinguir dentro de esta forma narrativa y

11. Evidentemente no es éste el lugar para la definición y revisión de tan atrayente y movedizo género. Un clásico en la bibliografía sobre el mismocuya principal limitación como ha señalado la crítica posterior, quizá resida en su limitación al modelo scottiano, es el texto de Lukács (1977). Remito asimismo a las monografías de Fernández Prieto (1988), Yáñez (1991), así como a la útil bibliografía de Jurado (2006), y en concreto para la novela histórica de estos momentos a Romero Tobar (1994: 375-388), Rubio (1977) y Almela (2006). 
en estas coordenadas históricas, diversas modalidades. En su monografía sobre este género (Ferreras, 1976), y dejando aparte el estudio de la que denomina novela arqueológica y episodio nacional, el crítico distinguirá entre tres formas distintas de novelas históricas que marcan la evolución del género desde ese primer prototipo scottiano, hasta otras formas en que la peripecia y aventuras acaban por desplazar la visión romántica del mundo característica de sus inicios y la recreación histórica, la cual se convierte en mero telón de fondo al servicio de la intriga y el suspense. La pervivencia de estas últimas tendencias -según la denominación de Ferreras novela histórica de aventuras y novela de aventuras históricas - se prolongará prácticamente hasta finales de siglo, de manera que pese a tratarse por lo general, de escritores menores, dicho crítico constata la existencia de un centenar de autores que publicaron obras de este tipo entre 1870 y 1900 (Ferreras, 1976: 212). Una especia de novela desde luego próxima o inmersa en lo que suele considerarse paraliteratura.

Es en esta última época -las décadas finales de siglo-, cuando Blasco Ibáñez da a la luz sus novelas históricas. Unos años en los que sin duda, las tendencias literarias del momento se caracterizaban por otros condicionamientos muy distintos. A tenor de que la obra considerada el mejor ejemplo de novela histórica española como El señor de Bembibre es de 1844 y que a partir de ella suele hablarse de la decadencia del género, vemos realmente cómo los comienzos de Blasco podrían ser catalogados como los propios de un autor rezagado. En el ámbito de la novela histórica, y dejando a un lado la poca incidencia en España de uno de sus subgéneros como la novela arqueológica ${ }^{12}$, el tipo de relato histórico que se impone especialmente tras el éxito de las obras de Pérez Galdós, es el episodio nacional. Por otro lado recordemos cómo a partir de los años 70 el interés se vuelca especialmente hacia el presente contemporáneo, de manera que Realismo y casi al mismo tiempo en España, Naturalismo, son las tendencias que dominan el panorama literario hasta finales de siglo. En los años así, que Blasco Ibáñez comienza a publicar estas primeras novelas, podríamos recordar tan sólo de algunos de los más destacados nombres del momento, títulos como Los Pazos de Ulloa (1886) y La Madre Naturaleza (1887) de Pardo Bazán, Su único hijo (1891) de Clarín, Miau (1888) de Galdós, La Puchera (1889) y Peñas arriba (1895) de Pereda, o Juanita la Larga (1896) de Valera. Unas obras que evidentemente tienen muy poco en común -y por supuesto, no entro en comparaciones relativas a la calidad artística- con esos primeros intentos novelescos del entonces joven autor valenciano. En el mismo las influencias literarias que se perciben

12. De la que Sónnica sería un claro ejemplo. 
con toda claridad son las de los autores y de la poética del Romanticismo, de forma que junto al mencionado nombre español de Fernández y González, no puede dejar de ser evocado uno de los grandes ídolos de Blasco, como el francés Víctor Hugo.

Como retrasadas producciones de un desvaído postromanticismo deben ser, pues, consideradas estas novelas históricas de Blasco, muy alejadas desde luego, de las polémicas y de la debatida cuestión naturalista de aquellos años. Una nueva forma de concebir la creación literaria a la que se incorporaría no obstante, pocos años después, el valenciano para trazar a partir de esos momentos una férrea línea divisoria entre aquellas primera juveniles obras románticas y su obra de madurez. Con todo, y desde luego no es Blasco el único caso, esas fuertes influencias románticas que marcaron sus inicios no desaparecerán totalmente en su obra posterior. De manera que en sus novelas bien puede apreciarse ese singular y curioso solapamiento o interrelación que se produciría en ocasiones entre Romanticismo y Naturalismo. $\mathrm{O}$ si se quiere y aun simplificadamente desde una perspectiva más amplia, entre imaginación y observación fiel de la realidad. El sustrato romántico tan explícito en estas primeras producciones, de hecho se prolongará en la posterior obra de Blasco y si bien este es tema que desborda asimismo las limitaciones del presente estudio, resulta tan patente su huella que podría trazarse en su obra la conjunción de dos de sus más fuertes influjos literarios como Hugo y Zola ${ }^{13}$. Incluso desde una perspectiva genérica más amplia que supera la visión de la pura periodización literaria, podría hablarse de esos dos modelos narrativos distintos que según la diferenciación en lengua inglesa, serían el romance y la novela. Si desde luego y como comprobaremos, en estas obras primeras el que se impone es el romance no puede decirse que éste desaparezca totalmente en sus obras posteriores ${ }^{14}$. Desde luego en sus otras novelas históricas no será difícil de percibir. Pero este, como se indicó más arriba, sería tema para otro estudio. El presente se centrará en el análisis de estas tres novelas concretas, insertas en ese corpus olvidado del gran autor valenciano.

13. La crítica de estos últimos tiempos ha incidido en la singular prolongación y sustrato romántico en el posterior Naturalismo, que un hombre de la época como Valera, ya señalara. Asimismo y en el caso específico de Blasco recordemos cómo desde la perspectiva de la distancia, en esa mencionada carta a Cejador el autor insistía en la fuerte influencia que en su obra tuvo Víctor Hugo, incluso superior según él a la de Zola.

14. Recordemos también la reconocida presencia y prolongación de recursos y motivos propios de la denominada novela folletinesca en la novela culta o artística, que tiene en la obra de Dickens, Dostoyevski o Galdós destacados ejemplos. 


\section{TRES NOVELAS HISTÓRICAS DIFERENTES}

Si nos atenemos al testimonio de Smith y Espinós, El conde Garci-Fernández sería una obra anterior a ;Por la Patria!, hecho que parece ratificar la elaboración de ambas, al presentarse esta segunda como una obra de mejor y más conseguida factura ${ }^{15}$. Habiéndonos referido más arriba a la catalogación genérica de las tres novelas, tan distintas entre sí, las mismas no obstante, podrían ser englobadas dentro de lo que Spang ha catalogado como novela histórica ilusionista, frente a la antiilusionista, más propia del siglo posterior (Spang, 1995). Articulada la primera según el modelo clásico tal como lo creó Scott, se caracterizará por los intentos de crear la ilusión de autenticidad y veracidad de lo narrado. Desde luego los rasgos relacionados con esta modalidad del género -implicación del narrador, mención al manejo de documentos...- se perciben en estas obras de Blasco, de las cuales las dos primeras presentan en sus títulos los nombres de los protagonistas, en esa exaltación del individuo propia de los autores románticos señalada por Spang. Distinto desde luego es el título de la tercera y ello sólo puede servir de indicio de la diferente naturaleza de dicha novela.

En El conde Garci-Fernández Blasco vuelve su mirada hacia la remota Edad Media para elegir como protagonista de su novela al hijo del famoso conde Fernán-González, fundador del estado de Castilla. En tal elección puede ser advertida la manera de actuar propia de los escritores románticos quienes con el fin de poder dar rienda suelta a sus imaginadas intrigas, solían escoger como héroes bien a personajes totalmente inventados ${ }^{16}$, o a personajes históricos de segundo plano. Desde luego comparado con su famoso padre, este Garci-Fernández aparece como una figura histórica más oscurecida $^{17}$, con la cual Blasco se permite elaborar un relato que dista mucho, desde luego, de su biografía real.

Siendo Garci-Fernández el protagonista claro de la presente obra, en la misma como en la que escribirá a continuación, el autor manejará a un segundo personaje que desarrollará una trama novelesca paralela a la principal. Ambas caracterizadas básicamente por las intrigas amorosas. La del segundo protagonista D. Juan de Sepúlveda, recrea un viejo tópico romántico: el del amor entre jóvenes pertenecientes a familias enemigas ${ }^{18}$.

15. Según testimonio de alguien tan próximo al escritor como Pilar Tortosa, El conde Garci-Fernández sería el manuscrito que Blasco en su escapada juvenil a Madrid, llevó para publicar. Tortosa, 1977: 68.

16. Recuérdese la famosa teoría de Lukács sobre lo que denominó héroe medio.

17. Sobre la elección y los problemas en la configuración de los personajes en las novelas históricas, véase Mata, 1995.

18. Una singular versión decimonónica del famoso tema popularizado por Bandello que el propio Blasco explotaría en más de una ocasión. Vgr. su cuento «La misa de medianoche». 
En general toda la novela aparece recorrida por temas, artificios y motivos propios del Romanticismo, y en concreto por aquellos procedentes en el ámbito de la narrativa histórica, del modelo scottiano, increíblemente latente aún en estas fechas. En el arranque mismo encontramos el viejo y explotado motivo del disfraz, duplicado además en la personalidad de ambos héroes ${ }^{19}$. Muy scottiano es también el personaje del bandido bueno y noble, aquí personificado en el hermano de Fernán Antolínez ${ }^{20}$, o la casi inexcusable presencia de la hechicera. Como en las obras del escocés y en general, en toda su descendencia posterior, el trazado de los personajes atiende a unos cuantos rasgos típicos y fijos que producen en definitiva, un limitado repertorio de figuras carentes de toda complejidad psicológica. Se diría que incluso en una ocasión, hasta el propio narrador se rinde a tal evidencia al definir a una de esas angelicales y perfectas heroínas femeninas como un «tipo acabado de la doncella feudal» ${ }^{21}$. Desde luego el héroe aparece claramente ensalzado, recordando incluso en su configuración, al prototipo del caballero andante; una especie esta, la de los viejos libros de caballerías con la que presenta no pocas relaciones la novela histórica romántica. Recordemos así, cómo el conde decide adoptar una identidad fingida para recorrer sus posesiones. En ese deambular de un espacio a otro, encontrará precisamente una caravana que suscita en él una reflexión más propia de un héroe caballeresco que de un personaje de su condición: «tal vez nos metamos en alguna aventura que disipe el tedio que en mí producen los negocios de Castilla» (IV: 340 ).

Estos personajes articulados en torno a muy pocos rasgos que los definen en su inmutable naturaleza -Argentina, la adúltera esposa, es desde luego el prototipo romántico de la mujer fatal que arrastra a la perdición al hombre, y su amante Lotario el más completo dechado de villano-, se caracterizarán además por unos registros lingüísticos que no pueden dejar de revelar la inexperiencia del joven autor. Estamos, desde luego, ante unos toscos intentos por reproducir un tipo de lenguaje que evoque de alguna forma la época recreada. Un aspecto este, el de la caracterización lingüística de sus personajes, por el que mostraría especial atención Blasco en sus

19. Si en este caso uno de ellos resulta ser el personaje histórico que da título a la obra, recordemos cómo en otras muchas novelas el disfraz se relacionaba también con famosos personajes históricos. Desde el propio rey Ricardo en Ivanhoe, hasta el Felipe II presentado en algún momento en El pastelero del Madrigal, la que se viene considerando una de las mejores obras de Fernández y González.

20. El motivo del apresamiento del personaje por los bandidos y su encierro en la cueva también se dio en novelas anteriores. Recuérdese el Sancho Saldaña de Espronceda.

21. Citaré siempre por la edición de Obras completas de Aguilar, indicando volumen y página (IV: 294). 
obras ya de madurez. Las primeras palabras, en esta ocasión pensamientos, del protagonista que nos llegan en estilo directo pueden ser buena muestra del tipo de lenguaje empleado por estos personajes: $-_{-i}$ Vive Dios!, que mi situación es magnífica-» (IV: 278). En general este tipo de monólogo en estilo directo $-\mathrm{y}$ recordemos que este estilo será el que domine en esta especie novelesca vinculándola de nuevo con la folletinesca- no será infrecuente en estas primeras obras de Blasco. Si bien es cierto ya en alguna novela posterior como La araña negra empezamos a percibir ligeras variantes, con la aparición de ese estilo indirecto libre que tan característico será de sus novelas de madurez. Como quiera que sea y considerando además los problemas anexos a este tipo de novela histórica evocadora de un pasado lejano, se puede decir que los diálogos presentados a lo largo de la obra responden a un tipo de lenguaje artificioso y poco natural que como ocurrirá también en el folletín, se desenvuelve por esos registros que podríamos catalogar de agudos, caracterizados por la imprecación y las frases exaltadas a tono con la propia peripecia repleta de lances efectistas. Un lenguaje que dista mucho desde luego de una lengua coloquial y natural. De hecho precisamente éste ha sido uno de los rasgos esgrimidos por la crítica para diferenciar el romance de la novela. Si aquél se caracteriza por la presentación de esos héroes y heroínas sometidos a un claro proceso de estilización, frente a ese hombre común propio de la novela, el lenguaje caracterizador de tales personajes debe asimismo diferir. Y es que si frente a ese héroe épico como estudiara Lukács, este nuevo héroe de la novela histórica parece menor, no cabe duda que seguimos situados en el mismo plano de estilización idealista.

Relacionado con esos viejos romances caballerescos, también en ocasiones se han vinculado las técnicas y artificios de este género, con aquellos viejos relatos de amor y viaje griegos ${ }^{22}$. Todos ellos caracterizados por presentar unas historias repletas de cambios, sorpresas, casualidades y asombrosas coincidencias y en general por la ausencia de ese viejo principio aristotélico de la necesidad o causalidad. Presentes también en su configuración diversas historias secundarias que se van vinculando a través de asombrosos nexos de relación, no es extraño que el narrador de El Doncel de Larra, acudiese por ejemplo, al término laberinto -de implicaciones tan cervantinas-, para referirse a la compleja cadena de sucesos presentada en dicha obra.

En general y esto no resulta algo novedoso en la historia literaria, la elaboración de este tipo de novela suele basarse en el principio de la re-

22. Véase por ejemplo, la introducción de Prieto a su edición de El señor de Bembibre (1974), o el comentario de Montesinos en relación con esa técnica de desaparición y reaparición de personajes, que hallamos en algunos de los Episodios galdosianos (1980, I: 106). 
unión de varias historias que más o menos convincentemente se van encadenando. Unas secuencias a veces desarrolladas de forma simultánea y que se conforman en muchas ocasiones, bajo la tradicional técnica del entrelazado. Presente este viejo recurso en la antigua épica y especialmente en los citados libros de caballerías, recordemos las críticas de un autor como Tasso por la pérdida de unidad en esa posterior épica culta que tiene en los poemas de Boiardo, y especialmente Ariosto, sus mejores exponentes. La narrativa romántica a tal respecto, podría ser alineada dentro de estas técnicas compositivas, encaminadas esencialmente a provocar el suspense e interés del lector. Si es cierto que en muchas de estas obras asistimos a un verdadero descontrol del autor en su manejo de las mismas, el caso de la presente novela de Blasco no es de los más llamativos. Un cotejo así desde tal perspectiva, de esta novela con la mencionada El pastelero del Madrigal de Fernández y González inclinaría la balanza a favor de Blasco, quien pese a su reconocida facilidad y naturaleza improvisadora a la hora de escribir sus novelas, mostró a la vez su preocupación e interés por el aspecto formal de las mismas ${ }^{23}$.

Relacionado con ese mismo deseo de mantener avivada la curiosidad del lector, aparecería esa brusca conclusión de los capítulos que paraliza la acción a menudo en el punto álgido de la escena. Algo que se dará con especial profusión en las novelas publicadas por entregas ${ }^{24}$ y que desde luego, tenía mucho que ver con la propia forma de aparición. También los mismos epígrafes de capítulos surgen como una especial forma de reclamo de la atención de los lectores (Baquero Goyanes, 1970: 110-112). Además del empleo de esas formas tan tradicionales como «En el que se ve...», o similares, muchos de los capítulos de El conde Garci-Fernández se caracterizan por su singular contundencia, a la manera de «En la boca del lobo», o por su curioso efecto sugerente -«Lo que puede verse y oírse a través de un agujero»-. Una manera de titular también plenamente romántica y que de alguna manera podría ser vinculada con la de otro escritor tachado también de rezagado como Pedro Antonio de Alarcón.

Si todos estos motivos se aprecian asimismo en la mencionada novela folletinesca, nuevamente podría trazarse otro paralelismo perceptible en la presente novela, consistente en la aparición de determinados episodios

23. Resultan significativos al respecto, los reproches que pese a la admiración que hacia él sentía, dirige a Balzac, por su falta de método a la hora de concebir sus novelas en algunas de las cuales, escribe «no existe para nada la unidad de acción, tan indispensable para la narración» (IV: 1215). Desde luego en sus novelas folletinescas no puede decirse que Blasco se atuviese a unos planteamientos serios y rigurosos acerca de la estructura de unas obras que por sus propias características, utilizan esas técnicas mencionadas de forma incontrolada y abusiva.

24. Esta misma apareció en el folletín de El Correo de Valencia. 
relacionables con la novela gótica que como Rubio señaló, están presentes en ambas modalidades narrativas (Rubio, 1982). Recordemos así el relevante episodio amoroso que tiene como escenario el barranco de las Brujas o la presencia por ejemplo, de ese tópico subterráneo oculto que da acceso al castillo.

De otro lado la configuración del narrador se ajusta también a la propia de la narrativa romántica ${ }^{25}$. Todavía no estamos ante ese Blasco creador de unos narradores que en gran medida se caracterizarán por su objetividad, conforme a esas exigencias de la poética naturalista de la que tan distanciado está aún el joven escritor de estos relatos históricos. El narrador de la presente obra es por tanto, un narrador intruso que suele dialogar constantemente con sus lectores, y al que no le preocupa destruir la ilusión de realidad de su ficción con expresiones del tipo «lo hemos visto al principio de esta novela» (IV, p.328), o «En los primeros capítulos de esta obra recordarán nuestros lectores» (IV, p.374). Las fórmulas del tipo «Hemos abandonado», «lo habíamos presentado», «Ya habrá comprendido el lector»... son por consiguiente, abundantes y con ellas la figura del narrador revela continuamente su presencia, en amistoso diálogo con sus lectores. Este narrador que no tiene pues, ningún reparo en dejarse ver y dejar constancia de sí, trazará también en algunas ocasiones esos particulares paralelismos en la relación pasado-presente, que tan frecuentes fueron en este género. Especialmente en aquellas novelas ambientadas en épocas alejadas, los escritores acudían a diversas estrategias para informar debidamente a sus lectores sobre circunstancias y sucesos necesarios para la comprensión del relato. Unas informaciones que evidentemente disminuirán y aún desaparecerán cuando se trate de una temporalidad próxima y que los lectores conocen bien. A tal respecto resulta significativo el arranque del cap. V: «En la Edad Media eran muy comunes las grandes bandas de malhechores...» (IV, p. 296). Inicio al que sigue un largo excurso en el que el narrador se detiene en presentar la situación de aquellos siglos en lo referente a esta concreta situación. También en el inicio del cap. X y a partir de una descripción bastante detallada del alcázar del conde, el narrador justifica las condiciones de este tipo de edificio por las circunstancias históricas. Especialmente curioso por lo demás, resulta otro comentario de la voz narrativa al presentar el voraz apetito de un personaje femenino y comparar a éste con las jóvenes actuales «anémicas y románticas». El romanticismo del escritor como se ve, iba más allá de su propia escritura para afectar a la visión de su propia realidad contemporánea.

25. Sobre las técnicas narrativas presentes en este género, vid. I. Román (I. 1988: 132 y ss.). 
Finalmente y en relación con este mismo motivo de la recreación del pasado histórico, no puede decirse que el mismo cobre especial relevancia en esta obra de Blasco, frente a lo que ocurrirá en otras novelas suyas posteriores. De esa esencial mixtura que constituye el cuerpo de toda novela histórica: ficción-historia, es desde luego el primer constituyente el que encuentra aquí su más amplio desarrollo. Caracterizada la época de este conde por las numerosas contiendas que este impetuoso y beligerante personaje mantuvo con los sarracenos a los que nunca se plegó frente a la actitud de otros nobles cristianos, las mismas si apenas son mencionadas en algún momento del relato. Si bien es cierto son precisamente algunos de estos episodios, aquellos en los que el relato cobra una mayor animación -no en balde Blasco destacaría en sus obras posteriores por su personales dotes descriptivas-. Recuérdese por ejemplo, la presentación de un combate entre cristianos y árabes en el cap.III, en el que además de las consabidas huellas épicas o caballerescas se aprecia la influencia de un autor que sería para él un auténtico ídolo como Cervantes. Esas «descomunales heridas» o «descomunal mandoble» recuerdan desde luego, el léxico cervantino sólo que -y en ello coincidirá con otros escritores románticos- despojado aquí de la ironía y humor propios de aquel autor ${ }^{26}$.

Por lo demás y como fue habitual en la novela histórica romántica, el narrador alude en ocasiones a los documentos y fuentes manejados, especialmente en ese epílogo en el que conforme a otra técnica narrativa muy decimonónica, se van atando todos los cabos. Si al referirse al final de su héroe reproduce literalmente un fragmento del historiador Mariana ${ }^{27}$, la novela concluye con la revisión panorámica de las vidas del resto de personajes que han conformado la esfera puramente novelesca del relato. Las frases finales con las que se remata la obra responden pues, en definitiva al uso del viejo tópico del manuscrito que ya desde los relatos caballerescos aparecía al servicio del interés del autor por crear esa ilusión de historicidad en sus lectores ${ }^{28}$. «Los antiguos documentos de que entresacamos la presente narración no dicen nada más sobre nuestros personajes, y por lo mismo nos creemos en la ineludible obligación de hacer punto final».

De Rodríguez de Montalvo a Blasco Ibáñez, la novela se muestra pues, como un género en el que pese a quebrantarse incluso la tradicional ley de la verosimilitud, al desarrollar un tipo de ficción caracterizada por lo

26. Especialmente curiosa es la recepción del Quijote en Estanislao de Cosca Bayo, de la que me ocupé en otro lugar (Baquero Escudero, 1986). La influencia cervantina en esta novela podría ser percibida también en la elección del nombre de Lotario. Sobre la influencia de Cervantes en Blasco véase Alberto Sánchez, 1999: 33- 61.

27. Fuente que ya utilizaría en su Hugo de Moncada.

28. Sobre la presencia de este viejo tópico en la novela histórica romántica véase Penas (1992). 
verdaderamente extraordinario, se pretende defender la autenticidad de lo presentado.

Frente a ese claro predominio de la aventura aquí fundamentalmente dirigida a unas intrigas amorosas, que aproximan esta obra a esas novelas históricas posteriores en las que predomina la pura acción novelesca, en ¡Por la Patria! (Roméu el guerrillero) Blasco se aparta de este tipo de relato para escribir lo que puede considerarse un episodio nacional. Realmente estaríamos ante lo que podríamos catalogar como una obra de circunstancias, pues la misma surgió como consecuencia de esos actos organizados en Valencia para rememorar la memoria de aquél héroe de Sagunto ${ }^{29}$. Si bien éste había fallecido hacía bastante años -en 1812-, sin embargo la mención al abandono posterior en que quedó su familia, denunciada como recoge el escritor al final de su obra, en 1861 por un periódico de la época, demuestra cómo se trataba realmente de un caso relacionado aún con una memoria próxima $^{30}$. Algo que de alguna forma podría vincularse con esas novelas, estas sí basadas en el aprovechamiento de circunstancias recientes, que, como señalara Rubio Cremades, gozaron de una inmediata acogida por parte de esos lectores todavía impresionados por los acontecimientos ${ }^{31}$.

Aunque más que con este tipo de obras surgidas a raíz de sucesos que tuvieron por su naturaleza, una gran recepción pública, Roméu debería adscribirse al ámbito de ese tipo de novela histórica regionalista que gozará de gran auge a lo largo de esta época. Si bien y al mismo tiempo, la novela de Blasco supone toda una exaltación general a la patria española ${ }^{32}$. De hecho y en esa altisonante dedicatoria colocada al frente de la obra, Blasco declara su intención de presentar «la gloriosa epopeya de la independencia española», de manera que en la obra convivirá la glorificación particular de un héroe valenciano, con la exaltación de la lucha de los españoles contra los franceses. En la presente novela el escritor dirigirá, pues, su atención tanto al héroe como a la masa colectiva representada aquí en el pueblo, algo que puede ser percibido en el mismo título de la obra. De manera que frente a la presencia única del nombre del héroe, en la novela histórica anterior, ahora Blasco optará por un título doble: ¡Por la Patria! (Roméu el guerrillero).

29. Sobre las circunstancias que rodearon a tal evento, puede verse León Roca (2002: 77-78). Sobre la experiencia biográfica de Blasco siendo niño, en una ejecución pública, vid. también Roca (2002: 45), si bien Tortosa niega que sus padres lo llevaran nunca a tan terrible espectáculo. Tortosa (1977. 30).

30. El escritor desde su presente, expresará sus quejas por el tratamiento dado al valiente guerrillero en Valencia.

31. Recuerda al respecto este crítico Los terremotos de Orihuela de Kosca Vayo o Jaime el Barbudo de López Soler (1977: 610).

32. Unos sentimientos conjuntos que pervivirían en el escritor a lo largo de toda su vida. 
En relación con el mencionado término con el que asocia su obra, «gloriosa epopeya», la caracterización del protagonista responde como precisa el narrador, al prototipo del héroe épico. En esa tradicional conmemoración poética en la descripción del personaje, escribe éste: «Era semejante en todo a un héroe de la antigua Grecia, con cara de Apolo y cuerpo de atleta» (IV. p. 122). Un tipo de comparación que manejará en otra ocasión -«cual los héroes de las antiguas epopeyas» (IV. p. 268)-, si bien el modelo épico medieval o incluso el caballeresco se deja ver también como en la obra anterior. Recuérdese así esa mención última a los hechos de ese colosal gigante que es el guerrillero apodado el Padre, cuyas hazañas escribe el narrador, resucitaban la memoria de los «paladines legendarios de la Edad Media» (IV. p. 273).

Si Roméu presenta un ideario basado en la defensa de tres valores tradicionales -religión, rey y patria-, que sin duda no coincide con el del propio autor, caso bien distinto es el de ese otro héroe secundario que protagoniza su propia intriga -cómo no de temática amorosa-, que es Luis Roca. En su exaltación de las ideas procedentes de Francia y en su presentación general de joven revolucionario que suscita los temores de su propia familia, puede percibirse sin duda el reflejo literario del mismo Blasco. La compleja peripecia amorosa de este segundo héroe, dice el narrador «estaba más llena de aventuras y trabajos que la de Persiles y Sigismunda (IV. p. 131), con lo que nuevamente podemos trazar el mencionado contacto de esta obra con una de las modalidades más antiguas del romance. La misma aparece al servicio de la acción propiamente ficticia de la obra que en la presente ocasión y frente a la obra anterior, no llega desde luego a imponerse a la relación de los sucesos históricos.

De nuevo nos encontramos pues, y especialmente en la esfera de lo puramente novelesco, con una trama repleta de incidentes que provoca la sorpresa del lector, con esos epígrafes llamativos y esos bruscos finales de capítulos, y con esas secuencias distintas que se van relacionando en asombrosas coincidencias. La técnica del entrelazado -«Nosotros le dejamos»-, volverá por tanto a ser manejada por ese narrador intruso que en sus apelaciones y diálogo frecuente con sus lectores, llega incluso a reproducir la voz de éstos -«¿Preguntáis si sus efectos son terribles?» (IV. p. 146)-.

A tal respecto los personajes no pueden dejar de presentar las características típicas de los personajes del romance, encontrando ejemplos tan claramente tradicionales como los de avaro escribano y su bella hija en los que se produce esa habitual correlación entre su retrato y su etopeya ${ }^{33}$. Si tal como

33. Enrique Miralles destacó al respecto tal tipo de configuración en los personajes alarconianos, de los que el Lucas de El sombrero de tres picos constituiría una auténtica excepción. Miralles, 1979: 307. 
ocurre en la novela folletinesca el mundo moral de estos personajes aparece conformado a través de un claro dualismo antitético ${ }^{34}$, sin embargo y pese a que el conflicto central de la novela se sustente en el choque entre esas dos fuerzas contrarias personificadas en españoles y franceses, advertimos algunas desviaciones. Aun cuando a lo largo de la obra el narrador en ese obvio procedimiento de manipulación ideológica -no se olvide el creciente proceso de politización en el género histórico-, no puede dejar de exaltar el valor y grandeza del bando nacional frente al enemigo intruso, siempre presentado de manera negativa, en algún momento de la obra se quebranta esta norma. Y si bien y como resulta previsible, la función del villano la desempeña un francés, recordemos cómo es presentado el oficial que de forma traicionera conseguirá apresar a Roméu: «El oficial que mandaba el grupo, joven, de rostro franco y simpático, debía pensar esto, por cuanto se ruborizaba y parecía tener reparo en avanzar» (IV. p. 245). Especialmente en el final de la novela, el ejército francés será presentado con unos rasgos de humanidad que rompen pues, con esa simplificadora visión de los hechos ${ }^{35}$.

Por lo demás y a tenor de que la novela recoge el enfrentamiento entre ambos bandos contrarios, con la presentación por consiguiente, de episodios de choque bélico, vamos a encontrar en ¡Por la Patria!, escenas protagonizadas por toda una masa colectiva caracterizadas por el movimiento, sonoridad y enorme plasticidad. Un tipo de escena que preludia a ese Blasco magistral artífice de cuadros de gran animación, protagonizados por un personaje múltiple. Como se señaló, el pueblo defensor de su independencia en lucha contra el agresor, puede considerarse de alguna forma también protagonista de la obra. Un protagonismo colectivo reflejado tanto en los soldados, como en los guerrilleros o en esos labriegos y hombres del pueblo que asoman asimismo a las páginas de la novela. Resulta curioso respecto a estos últimos que al presentar en el mismo inicio de la obra, cap. II, a algunos de esos labriegos innominados, precise el narrador: «dijeron el lengua valenciana, los dos hombres que habían llegado primero» (IV. p.127), para desarrollar el coloquio entre éstos y Roméu en el mismo estilo directo. No cabe duda que el escritor distaba pues, mucho de compartir los principios naturalistas que tan diferentes resultados producirán en esa novelas posteriores del ciclo valenciano, en lo que concierne a la reproducción de las palabras de los personajes.

De entre esa masa colectiva destaca de forma especial un singular trío de personajes, guerrilleros al mando de Roméu, y conocido por su

34. Romero Tobar ha desarrollado tal aspecto en su ya clásica monografía sobre lo que él denomina novela popular (1976).

35. Véase el cap. XXIV: «La muerte del héroe». 
peculiar naturaleza bajo el sobrenombre de la Santísima Trinidad. Tres figuras en las que se aúna como indica el narrador «lo grotesco» con «lo sublime» (IV. p.151). Titulado el cap. VI con tal curioso apodo, el mismo aparece íntegramente dedicado a la minuciosa descripción de estas tres figuras. Unas descripciones realmente completísimas y pormenorizadas en las que cabría percibir el manejo de unas técnicas descriptivas propias del más detallado realismo. Desde luego y en relación con el retrato de tales personajes sí podría hablarse de ese «realismo pretérito» del que hablara Sebold, al referirse a la singular concordancia entre tradición literaria y moderno realismo, en la novela histórica romántica ${ }^{36}$.Tales figuras tan pormenorizadamente presentadas -ese hercúleo gigante de «descomunales manazas», ese sagaz y valiente hombre y ese muchacho «tipo del pillete clásico tantas veces pintado por célebres autores» (IV. p. 153)-, se convertirán a raíz de su aparición, en personajes importantes en el desarrollo de la trama cuya presencia contribuye sin duda, a incentivar la intriga tanto novelesca como histórica. Con ellos partirá así Luis Roca, a la búsqueda de la perdida familia de Roméu, protagonizando uno de los episodios más animados y mejor trazados del relato. En el mismo se nos presenta el dificultoso y peligroso viaje de esta comitiva por unas tierras nevadas que obstaculizan su avance. El escenario por el que se desenvuelve la acción aparece en esta ocasión vívidamente descrito, frente a ese mero telón de fondo de la tópica ambientación histórica de la novela anterior $^{37}$. Y es aquí donde vamos a encontrar un peculiar atisbo de uno de los rasgos que mejor singularizarán la escritura literaria de Blasco: la atención concedida a la descripción de ambientes, aquí en concreto, al paisaje en el que se mueven los personajes. Si bien es cierto todavía seguimos encontrando fragmentos descriptivos concebidos en la más pura retórica romántica $^{38}$, no lo es menos que en ;Por la Patria! vamos a encontrar determinados pasajes que preludian desde luego, al mejor Blasco. En ese capítulo mencionado en que los personajes inician la peligrosa búsqueda de la familia de Roméu -cap. VII, «La Senda del Diablo»-, el narrador

36. Si bien él se refiere y analiza ejemplo propios de la primera tendencia scottiana, podríamos hacer extensivas sus afirmaciones al género del episodio nacional mucho más próximo claro está, al realismo novelesco. Por lo demás ya Amado Alonso en su clásica monografía sobre la novela histórica, se referiría a la presencia en la misma de la dualidad libre fantasía y objetividad.

37. El capítulo inicial de la novela con la detallada descripción de una Valencia solitaria, tras su rendición a los franceses, resultará toda una premonición respecto al mayor dominio del autor en el manejo de la descripción. Su contraste con el arranque de El conde Garci-Fernández es bastante evidente.

38. Y recuérdese la singular correlación tan típica de aquélla, entre situación de los personajes y estado de la naturaleza, en el cap.I en el que los valientes y rebeldes españoles se reúnen clandestinamente, mientras afuera estalla una violenta tormenta. 
sabrá conjugar el mantenimiento del suspense, con el desplazamiento de los personajes a través de esas tierras nevadas, y la reproducción cómo no de sus diálogos, en estilo directo, con acertadas pese a su parquedad, descripciones paisajísticas.

Azotados por un frío temporal, los personajes avanzan dificultosamente en un accidentado camino, en medio del crepúsculo. Precisamente los leves toques descriptivos referidos al progresivo avance de la oscuridad, relevan esa particular habilidad artística de Blasco para apresar los diferentes efectos de la luz en el paisaje. Inmersos en medio de una fuerte nevada, escribe el narrador:

El paisaje presentaba una monotonía fúnebre. Solo alguna vez, de una como joroba de la nieve que se veía a un lado o a otro del camino, y que era alguna choza o cabaña, salía un humo azulado que se desvanecía inmediatamente en el espacio (IV. p.157).

En ese avance de la tarde «La luz amarillenta y turbia que transparentaba aquel cielo oscuro y monótono, semejante a una bóveda de plomo, se iba desvaneciendo por minutos» (IV. p. 157). Y con la llegada de la noche la luz «absorbida rápidamente por la sombra, y la bóveda celeste cada vez se hacía más oscura. El suelo recubierto de nieve comenzaba a reverberar una extraña claridad» (IV. p. 159).

El capítulo concluye con un nuevo efecto descriptivo basado en el contraste de luces y color. Los personajes cerrada la noche, consiguen refugiarse en el interior de una cueva:

Entre tanto la nevada continuaba, y el negro espacio que recortaba la entrada de la cueva estaba surcado continuamente en todas las direcciones por puntos blancos, que revoloteaban semejantes a mariposas hijas de las tinieblas (IV. p.161) ${ }^{39}$.

El manejo del símil tan habitual en las descripciones posteriores de las obras de Blasco (Mas, Mateu, 2001: 156), se aprecia, pues, aún tímidamente en algunos de los fragmentos de esta novela. Y no es éste el único episodio de la obra en el que la presentación de la naturaleza adquiere relieve. Aun cuando evidentemente no estamos ante un caso como el tan mencionado de El señor de Bembibre en el que el paisaje recibe un trata-

39. En novelas posteriores, el manejo del símil adquirirá desde luego, una más compleja y brillante elaboración. Compárese el texto reproducido, con éste de Entre naranjos: «Rafael se sentía intimidado por aquella voz ligeramente burlona, que parecía poblar la oscuridad de mariposas de brillantes colores». 
miento verdaderamente excepcional ${ }^{40}$, considerando que es Blasco quien escribe estas páginas, uno no puede dejar de percibir ese singular detenimiento en una obra en la que impera la acción constante, en la descripción de la naturaleza valenciana. Incluso en la elección de la técnica de presentación de tal paisaje podríamos trazar conexiones dentro de la obra novelesca de Blasco.

Encontrada la familia de Roméu y dejada bajo la protección de un ermitaño, los personajes prosiguen su viaje por distintos lugares de la provincia de Valencia. A la borrasca anterior sigue ahora una hermosa mañana más propia de la estación primaveral que de aquellas fechas.

\begin{abstract}
A pesar de que la tierra estaba desnuda, el paisaje tenía la expresión alegre que se retrata en el rostro de un viejo un día de buen humor.

Los árboles estaban desprovistos de hojas; los prados no tenían hierba; la llanura y el monte no estaban matizados de verde, pero el sol se encargaba de alegrarlo todo, y aquí doraba los extremos de las escuetas ramas, allá se reflectaba en el árido peñón, haciéndolo brillar como un gran bloque de metal, y más abajo centelleaba en las mil chispas del riachuelo que, engrosado su caudal de aguas por la nieve, saltaba de piedra en piedra para perderse en desconocidos parajes (IV. p.179).
\end{abstract}

Este fascinante espectáculo de la naturaleza, precisa no obstante, inmediatamente el narrador, sólo es percibido por Luis quien con su fondo de poeta «contemplaba con atención aquel magnífico paisaje», a diferencia de la Santísima Trinidad a quienes sólo les importaban las ventajas prácticas «y el único interés que para ellos ofrecía el día era el poder caminar por terreno seco y no hundiéndose en la nieve como en los días anteriores» (IV. p. 179).

Incluso más adelante y en circunstancias aún más excepcionales, el narrador vuelve a utilizar también de alguna forma, esta técnica presentativa relacionada con un personaje reflector para introducir una nueva descripción paisajística. Formado el escuadrón de guerrilleros para un próximo combate, emprenderán de nuevo la marcha. Un avance que tiene lugar asimismo en el crepúsculo vespertino.

La tarde comenzaba a declinar. Los rayos del sol herían a los guerrilleros casi horizontalmente, prolongando sus sombras de una manera gigantesca.

El horizonte empezaba a cubrirse con esas nubes rojas y de polvo de oro que anuncian la puesta de sol.

40. Prieto en su edición del texto habla de la descripción de los paisajes regionales que vincula con un modelo distinto, como el de Los novios de Manzoni. Véase también la edición de la novela de Rubio Cremades (1986) y el estudio de Alonso Soane (1985). 
El paisaje se bañaba en la luz de color anaranjado que llenaba el espacio, y las moscas y los insectos que revoloteaban en él brillaban envueltos en aquella como si fueran moléculas de oro.

Era una tarde hermosísima, más propia para ser admirada por poetas y artistas que por guerreros que dentro de poco rato iban a derramar su sangre o a sembrar la muerte.

A pesar de esto, Roca se extasiaba en la contemplación del paisaje, y sentía esa oculta emoción que todos los artistas experimentan ante los hermosos espectáculos de la naturaleza (IV. pp.212-213).

Aun de forma tímida y fugaz, en Roméu encontramos ya la presencia no sólo de esas descripciones en que movimiento, y especialmente colores y efectos de luz resaltan de forma especial, sino también de esa técnica que consiste en vincular la pausa descriptiva con la mirada de uno de los personajes. Algo que adquirirá un más amplio desarrollo en una de esas novelas también de su época repudiada, La araña negra. En la Parte tercera de la misma encontramos un capítulo significativamente titulado «Sinfonía de colores» que supone una verdadera anomalía por lo que tiene de ruptura en el ritmo trepidante de la acción novelesca. Se trata de un capítulo verdaderamente excepcional en una novela folletinesca porque constituye una demorada interrupción de la intriga, al constituirse como una larguísima descripción del paisaje valenciano. Un verdadero oasis que no puede menos de asombrar al lector de la obra y que aparece en este caso precisamente justificado, por la técnica mencionada del personaje reflector. La joven y reprimida María, encerrada desde su más tierna edad en un convento, sólo disfrutaba con las furtivas escapadas a la azotea del mismo desde donde gozaba con la estática contemplación del paisaje. Una visión en la que el escritor manejará ya los efectos sinestésicos que reproduciría en la primera de sus novelas reconocidas, Arroz y tartana. La similitud del presente capítulo de La araña negra con el cap. VI de esta otra novela, en la que el desgraciado pretendiente Andresito, contempla esa «sinfonía de colores» del paisaje, desde el balcón de la finca solariega, es innegable.

Que estas novelas de iniciación del autor valenciano constituyeron pues, su taller de aprendizaje en que ya pueden descubrirse algunos de sus posteriores y más característicos aciertos artísticos, parece bastante claro ${ }^{41}$, aun cuando tales rasgos aparezcan prácticamente encubiertos y diluidos en la exuberancia romántica que guía la pluma del autor durante estos años.

41. Y pensemos tan sólo en la subrayada calidad impresionista de algunas de esas descripciones de sus novelas inmediatamente posteriores, conseguida especialmente por el manejo de los efectos de la luz. 
Si en El conde Garci-Fenández domina sin duda lo novelesco sobre lo propiamente histórico, si en iPor la Patria! tales planos aparecen mucho más equilibrados, en ;Viva la República! puede hablarse del destacado relieve de lo histórico sobre lo ficticio. Elegido por el escritor un tema que como vimos, tocaba muy de cerca sus convicciones más arraigadas, la exaltación de los principios revolucionarios y republicanos desborda inconteniblemente la obra, hasta el punto de llegar a inmovilizar -y ello resulta sumamente excepcional tratándose de una obra de carácter folletinesco-, la propia acción novelesca. Recuérdese, por ejemplo, el cap. XXI, Parte Primera, en que se presenta a Marat cuyo larguísimo discurso en defensa de sus convicciones ocupa prácticamente dicho capítulo, o ese extenso relato de pura información histórica que hace Camilo Desmoulins al español Guzmán, sobre la sublevación del pueblo y la toma de la Bastilla -cap. X, Parte Primera-. Salvadas desde luego las distancias, ya que el personaje narrador se muestra como directo testigo de acontecimientos recientemente vividos, puede percibirse en tal capítulo esa técnica de relato histórico enmarcado, que utilizaría Blasco en algunas de sus últimas novelas históricas ${ }^{42}$.

Respecto a las mencionadas figuras históricas incorporadas en la ficción novelesca, no puede decirse que sean sólo ellas dos las presentes en la misma. Una larguísima galería de tales personajes recorre las páginas de la obra -Danton, Robespierre, el abate Marchena...-, entre los que puede ser incluido el propio Napoleón. La aparición del mismo concluye de forma bastante efectista uno de los capítulos de la novela, al presentarse ese extraño casero del protagonista, teniente de artillería en situación pasiva, como Napoleón Bonaparte (cap. VIII. Parte Primera). Un personaje que volverá a reaparecer en circunstancias de gran tensión (cap. III. Parte Tercera), para volver a surgir en ese concluyente epílogo de la obra. Sumamente curiosa resulta también la participación de Goethe en una de las batallas finales de la novela (cap.VII. Parte Tercera), como singular testigo presente en ella. Aunque sin duda, el testigo principal en los más relevantes hechos históricos, es el protagonista ficticio del relato quien observará en toda su confusión y crudeza, los principales sucesos originados por la revolución ${ }^{43}$.

Ese Félix Guzmán -nuevo álter ego del joven Blasco-, es un español huido por causa de la persecución inquisitorial y que comparte los anhelos revolucionarios del pueblo francés. Antepuesto al arranque propio de

42. En El Papa del mar y A los pies de Venus y frente a lo que ocurre aquí, los dos planos aparecen completamente desvinculados.

43. Un recurso que usarían tanto Stendhal como Tolstoy - dos escritores bien conocidos por el autor-, en algunas de sus más famosas novelas. Recuérdese asimismo, cómo el propio Blasco estaría posteriormente en los escenarios de la guerra, como testigo privilegiado (Roca, 2002: 410-411). 
la novela -como hará también en La araña negra-, aparece un prólogo en el que se presenta la situación de tal joven condenado por la Inquisición y su huida a París. Un preámbulo que conforme a esa técnica tan habitual en la literatura satírica presenta el viejo procedimiento de la lectura al revés que revela desde luego, las convicciones e ideas del autor. De hecho la ideología del mismo queda totalmente patente a lo largo de la novela, por la actitud mantenida por el narrador. Y no sólo por esos excursos en que se manifiesta de manera explícita - «los reyes solo son imponentes cuando sus pueblos los contemplan prosternados, pero cuando se alzan poniéndose a su nivel, entonces solo ven, en cada uno de ellos, un hombre cualquiera agitado por la zozobra y conmovido por el terror» (V. P. 1044)-, sino por la propia manipulación de los hechos y sobre todo, la configuración de personajes. Realmente a estas primeras novelas del autor valenciano convienen perfectamente los testimonios que años después expresaría el escritor, contrastando la forma en que Zola concibe a sus personajes, con la propia de los autores románticos. Comentará así Blasco en una de esas conferencias dadas en Buenos Aires, en esta ocasión sobre el escritor naturalista:

\footnotetext{
En la escuela del romanticismo, el autor aparece a cada instante en escena, entre bastidores, hablando con todos y hablando por boca de todos. Se ven los hilos del que mueve a los personajes, como se veía la acción de Maese Pedro en el retablo aquel de que Cervantes nos habla en Don Quijote (IV. p. 1.238).
}

Desde luego ante tan importantes acontecimientos históricos, no cabe duda acerca de la actitud del narrador, en absoluto objetiva ni imparcial, aun cuando no silencie e incluso llegue a condenar los horrores consecuencia de los hechos de esa fuerza desbordada que es la masa popular.

La consciente selección y especialmente la morosa detención en la presentación de las atrocidades de los partidarios del antiguo orden, representados en los feroces y sanguinarios bretones, son claros indicios de la manipulación ideológica que domina la obra. Resulta curioso respecto a la descripción de los horrores llevados a cabo por estos últimos -esa muchedumbre enardecida de fanáticos-, la aparición de determinadas escenas que bien podrían catalogarse de naturalistas, por lo descarnadas y repulsivas. Los tormentos que sufre ese gigantesco Goliat apresado por los bretones, alcanzan unos extremos verdaderamente nauseabundos, por el detallismo descriptivo. Y así si una pedrada acaba de aplastarle un ojo, destacándose en su rostro como «un horrible agujero la vacía cuenca, de la que colgaban rojas piltrafas» (V. p. 1477), cuando finalmente la multitud se abalanza sobre él, convierte su cadáver «en una masa informe, pegajosa y aplanada, en una papilla cuyos jugos absorbió la tierra y en la cual mezclá- 
banse los músculos aplastados con los fragmentos de hueso y los harapos de tela» (Ibíd.). Salvadas las distancias, podríamos recordar el trágico final de esos pescadores que viajan con los protagonistas, en la escena final de Flor de $\mathrm{Mayo}^{44}$.

De otro lado en esas vívidas descripciones de los más importantes sucesos históricos -tanto en el derrocamiento de la monarquía, como en la posterior lucha contra los insurrectos realistas-, abundan evidentemente las escenas protagonizadas por toda una masa colectiva y caracterizadas por el movimiento y confusión constante. Una colectividad que alcanza un papel relevante a tenor como se señaló, del relieve de lo histórico sobre la acción novelesca. En este sentido las descripciones tanto de los enfrentamientos como del propio ambiente en que se desenvuelve la acción, adquieren en esta novela un destacado lugar. En esa minuciosa presentación por ejemplo, del Barrio y mercado de St. Germain no es difícil percibir los recuerdos del joven Blasco exiliado también forzoso en París unos años antes, y que recrea con logrado detallismo aquellos escenarios.

Paralelamente al discurrir de tan importantes acontecimientos históricos, transcurre la intriga propiamente novelesca. Aunque como en los dos casos estudiados habría que hablar de intrigas en plural, ya que junto al héroe principal aparece otro secundario: Santiago Vadier. Ambos protagonizando sus respectivas historias amorosas que cómo no, se encadenan casualmente. Nos movemos de nuevo en el ámbito del tradicional romance, en el que surgen motivos típicos como los disfraces ${ }^{45}$, la reaparición constante de personajes -esa figura del villano representada aquí por un envilecido marqués-, sorprendentes casualidades, presencia aún de la hechicera, conformación absolutamente maniquea de personajes... etc. Asimismo aparece protagonizado por Guzmán un motivo temático que explotaría en otras obras Blasco: la escisión del personaje entre un amor puro y su atracción hacia la bella y famosa cortesana. Un personaje este último acompañado de su propia historia -la también tópica víctima del libertinaje aristocrático-, y que no adquiere los perfiles negativos que tendrá el personaje de similar función de una de las tramas que constituyen La araña negra ${ }^{46}$. Es al presentar a esta última figura cuando el narrador traza una de esas típicas descripciones de inventario de su lujosa estancia, tan características como estudiara Romero Tobar, de las novelas populares (1976: 145). Precisamen-

44. El motivo del detallismo particularizador en los combates y choques bélicos entre personajes, no resulta por otro lado, novedoso en la historia literaria. Baste recordar la particular afición por tal tipo de escenas en el universo épico.

45. Y no parece casual la mención a las obras de Beaumarchais al respecto.

46. En la misma y en el final, uno de los personajes Juanito Zarzoso, aparece también escindido entre dos mujeres. 
te uno de los episodios de la novela en que aparecen bien interrelacionadas las dos esferas que constituyen la obra -ficción e historia-, tiene que ver con la difícil situación de Guzmán en su encuentro con ambas mujeres. En esa cita que se dio el pueblo en el Campo de Marte y en donde se produciría una encarnizada matanza, se suman y compenetran la tensa situación política con la no menos tensa intriga amorosa personal del héroe. Capítulos de gran intensidad dramática (XXIV y XXV. Parte Primera), en los mismos el héroe se ve necesariamente abocado a tomar una decisión que en la presente ocasión cae del lado de la joven casta e inocente ${ }^{47}$.

Por lo demás en el desenlace de la obra, el escritor no puede menos que proyectar sus desengañadas conclusiones respecto a los resultados posteriores de este importante momento de la historia de la humanidad, en los sucesos de sus dos héroes. Acudiendo al todavía scottiano recurso del fuego en situaciones dramáticas, el protagonista ve a su amada, y a su amigo y la suya consumidos sin remedio en medio de un devastador incendio. Él mismo se verá asimismo impelido por las circunstancias posteriores a quitarse la vida, desesperado por su vanos intentos de acabar con la corrupción que ha invadido el poder.

Las palabras últimas del narrador en ese epílogo que cobra aquí una mayor importancia que en las dos novelas revisadas, no sólo suponen una contundente y final revisión de todo lo mostrado en el desarrollo de la novela, sino también una prospección sobre acontecimientos futuros necesariamente conocidos por los lectores: «La República, que tanto costaba a la Francia, siguiendo la tortuosa corriente de su destino, habría de perderse en la basura de un Directorio primero, y después en la de un Imperio, que solo fue una locura gigantesca» (V. p. 1.516). Esos hechos aludidos que desbordan los límites cronológicos impuestos al presente relato son aprovechados pues, por el escritor quien desde su situación privilegiada se vale de ellos para afianzar aún más sus intereses ideológicos.

Que Blasco los tenía y que son patentes a lo largo de tan voluminosa obra, es algo que no admite discusión, por lo que junto a su carácter de novela folletinesca e histórica, la presente obra compartirá también rasgos de la novela de tesis, por lo demás bastante presentes en muchas novelas de la época romántica.

¡Viva la República!, como Roméu, como El conde Garci-Fernández no cabe duda pues, que son productos directamente relacionados con tal tendencia literaria muy lejana ya de la que impera en esas décadas de los 80

47. Muy distinto desde luego, resultará el tratamiento que el autor concederá a este tema en esa novela escrita varios años después que es Entre naranjos, en donde el trío amoroso adquiere una configuración muy diferente a la de estos románticos personajes. 
y 90 en que el escritor valenciano se descubre como creador literario. Que además de presentarse dentro de esta situación de rémora, las mismas son desde luego, muy inferiores al resto de su producción no parece que resulte hoy algo discutible. Y sin embargo, y pese a todo ello, en las tres se advierte esa portentosa inventiva que nunca abandonaría al autor, capaz de sostener unas intrigas novelescas merecedoras siempre del interés del lector. Como también aun de forma más o menos balbuciente, podemos encontrar ya aquí a ese escritor que sabe pintar con toda certeza esas escenas de gran movimiento y viveza protagonizadas por un personaje colectivo, o esos paisajes y ambientes en que los efectos especialmente de colorido y luz, son agudamente percibidos. Recordemos al respecto sus testimonios en esa famosa carta a Cejador, sobre la obra de Zola. Allí elogiaba especialmente en sus novelas, la pintura no de cuadros, sino de frescos enormes, para precisar: «¿Quién como él supo mover y hacer vivir las muchedumbres en las páginas de un libro?» Incluso a la hora de destacar algunos momentos de las obras del autor francés concentraba su admiración en la descripción de las muchedumbres de Germinal, o el jardín del Paradou. Aun cuando en las novelas aquí analizadas esos grandes frescos presentados tengan que ver especialmente con la descripción de grandes confrontaciones bélicas -las luchas entre cristianos y moriscos, o franceses y españoles, o la enfebrecida reacción del oprimido pueblo francés-, en ellas puede atisbarse la maestría del escritor que sabrá describir con admirable destreza en las obras inmediatamente posteriores, a ese personaje colectivo que es el pueblo valenciano que tan bien conoce, en sus costumbres, festejos, o en su incansable lucha con el mar. Como también puede apreciarse en estas novelas de aprendizaje, pese a su esporádica aparición, la fascinación por el paisaje y por los efectos provocados por los cambios de la naturaleza que sólo una mirada sensible es capaz de percibir.

$\mathrm{Si}$ a todo ello unimos el temprano interés del joven Blasco por novelar la historia que se mantendrá a lo largo de su posterior producción literaria, puede que esta rápida revisión por estas tres obras olvidadas no haya sido del todo infructuosa, y que incluso pudiera merecer el perdón del propio escritor por haber violentado su explícito repudio de ellas. 


\section{BIBLIOGRAFÍA}

Alborg, Juan Luis, Realismo y Naturalismo. La novela III. Armando Palacio Valdés-Vicente Blasco Ibáñez, Madrid, Gredos, 2001.

Almela, Margarita, «La novela histórica española durante el siglo XIX», en J. Jurado Morales (ed.), Reflexiones sobre la novela histórica, Universidad de Cádiz, 2006, pp.97-141.

Alonso Seonne, $M^{\mathrm{a}}$ José, «Aspectos del romanticismo de Enrique Gil en El señor de Bembibre», Alfinge, 3 (1985), pp.125-144.

Anderson, Chistopher L. y Paul Smith, Vicente Blasco Ibáñez: An Annotated Bibliography 1975-2002, Juan de la Cuesta, Newark, Delaware, 2005.

Anguix Vilches, Laia, «Sónnica la cortesana. Melodías de amor y muerte en el Sagunto romano», Arte y Libertad, 9 (2005), p. 5.

BAQUERo Escudero, Ana L., «Cervantes y la novela histórica romántica», Anales Cervantinos, XXIV (1986), pp.179-192.

BAQUero Goyanes, Mariano, Estructuras de la novela actual, Barcelona, Planeta, 1970.

Blasco Ibáñez, Vicente, Obras completas, Madrid, Aguilar, IV, 1979.

—. Obras completas, Madrid, Aguilar, V, 1978.

Buendía, Felicidad, Antología de la novela histórica española (18301844), Madrid, Aguilar, 1963.

EsPinós Quero, Antoni, La obra literaria de Vicente Blasco Ibáñez, Diputación de Valencia, 1998.

Fernández Prieto, Celia, Historia y novela: poética de la novela histórica, Pamplona, Eunsa, Universidad de Navarra, 1998.

Gil y Carrasco, Enrique, El señor de Bembibre, A. Prieto (ed.), Madrid, Novelas y Cuentos, 1974.

—. E. Rubio Cremades (ed.), Madrid, Cátedra, 1986.

Gómez DE BAQUero, Eduardo (Andrenio), El Renacimiento en la novela en el siglo XIX, Madrid, Editorial Mundo Latino, 1924.

González Blanco, Andrés, Blasco Ibáñez. La Novela Corta, Año V, 1920.

Jurado Morales, José, «Recuento bibliográfico de la novela histórica», en J. Jurado Morales (ed.), Reflexiones sobre la Novela Histórica, Universidad de Cádiz, 2006, pp. 391-437.

León Roca, José Luis, Vicente Blasco Ibáñez, Ajuntament de Valencia, 2002.

LuKács, Georg, La novela histórica, trad. J. Reuter, México, Ediciones Era, 1977.

Mas, José y M. ${ }^{a}$ Teresa Mateu, Vicente Blasco Ibáñez: ese diedro de luces $y$ de sombras, Valencia, Biblioteca Valenciana, 2001. 
Mata Indurain, Carlos, «Retrospectiva sobre la evolución de la novela histórica», en Spang, Arellano y Mata (eds.), La novela histórica. Teoría y comentarios, Navarra, Eunsa, 1995, pp.13-63.

-. «Las novelas históricas de Vicente Blasco Ibáñez: En busca del gran Kan, El Caballero de la Virgen, Vicente Blasco Ibáñez. La vuelta al Siglo de un novelista. Actas del Congreso Internacional celebrado en Valencia del 23 al 27 de nov. de 1998, Valencia, 2 vols., 2000, I. pp. 419-435.

Miralles, Enrique, La novela española de la Restauración (1875-1885): sus formas y enunciados narrativos, Barcelona, Puvill-Editor, 1979.

Montesinos, José F., Galdós, Madrid, Castalia, I., $2^{\mathrm{a}}$ ed., 1980.

OlezA, Joan, «Novelas mandan. Blasco Ibáñez y la musa realista de la Modernidad», Vicente Blasco Ibáñez. La vuelta al Siglo de un novelista. Actas del Congreso Internacional celebrado en Valencia, Valencia, 2 vols., 2000, I, pp.17-51.

Pitollet, Camille, «Cómo escribí el libro sobre Vicente Blasco Ibáñez», Boletín de la Biblioteca Menéndez Pelayo, XXXIII (1957), pp. 221365.

Penas, Ermitas, «Discurso cervantino y novela histórica romántica», Anales Cervantinos, XXIV (1992), pp. 139-156.

Román, Isabel, Historia interna de la novela española del siglo XIX, Sevilla, Alfar, 2 vols., 1988.

ROMERo TOBAR, Leonardo, La novela popular española del siglo XIX, Madrid, Juan March, Ariel, 1976.

—. Panorama crítico del romanticismo español, Madrid, Castalia, 1994.

Rubio Cremades, Enrique, «Novela histórica y folletín», Anales de Literatura Española, 1 (1982), pp. 269-281.

- «La novela histórica del Romanticismo español» en G. Carnero (coord.), Historia de la Literatura Española S. XIX (I), Madrid, Espasa Calpe, 1997, pp. 610-642.

- Panorama crítico de la novela realista-naturalista española, Madrid, Castalia, 1994.

Sánchez, Alberto, «Blasco Ibáñez, Cervantófilo», Don Quijote, ciudadano del mundo y otros ensayos cervantinos, Institució Alfons el Magnànim, Diputació de València, 1991, pp.33-61.

SEBold, Rusell P., La novela romántica en España, Salamanca, Ediciones Universidad de Salamanca, 2002.

Smith, Paul, Vicente Blasco Ibáñez. An Annotated Bibligraphy, London, Grant \& Cutler, 1976.

SPANG, Kurt, «Apuntes para una definición de la novela histórica», en Spang, Arellano y Mata (eds.), La novela histórica. Teoría y comentarios, Navarra, Eunsa, 1995, pp. 65-114. 
Talens Vivas, José Manuel, «Una revisión de la novela histórica de Blasco Ibáñez» Vicente Blasco Ibáñez. La vuelta al Siglo de un novelista, Actas del Congreso Internacional celebrado en Valencia, 2 vols, Valencia, 2001, I, pp. 436- 443.

Tortosa, Pilar, La mejor novela de V. Blasco Ibáñez: su vida, Valencia, Prometeo, 1977.

YAÑEZ, María-Paz, La historia: inagotable temática novelesca, Peter Lang, 1991.

ZamacoIs, Eduardo, Vicente Blasco Ibáñez, La novela mundial, Año III, 1928.

ZeLlers, Guilermo G., «Influencia de Walter Scott en España», Revista de Filología Española, XVIII, 2 (1931), pp. 149-162.

—. La novela histórica en España 1828-1850, New York, 1938. 